\title{
Review
}

\section{Discovery of structurally diverse and bioactive compounds from plant resources in China}

\author{
Sheng-ping YANG, Jian-min YUE* \\ State Key Laboratory of Drug Research, Shanghai Institute of Materia Medica, Chinese Academy of Sciences, Shanghai 201203, \\ China
}

\begin{abstract}
This review describes the major discoveries of structurally diverse and/or biologically significant compounds from plant resources in China, mainly from the traditional Chinese medicines (TCMs) since the establishment of our research group in 1999. In the past decade, a large array of biologically significant and novel structures has been identified from plant resources (or TCM) in our laboratory. The structural modification of several biologically important compounds led to more than 400 derivatives, some of which exhibited significantly improved activities and provided opportunities to elucidate the structure-activity relationship of the related compound class. These findings are important for drug discovery and help us understand the biological basis for the traditional applications of these plants in TCM.
\end{abstract}

Keywords: natural products; plant resources; traditional Chinese medicine; bioactive compounds; structural modification; structureactivity relationship

Acta Pharmacologica Sinica (2012) 33: 1147-1158; doi: 10.1038/aps.2012.105; published online 3 Sep 2012

\section{Introduction}

Natural products have long been used by humans, especially in the healthcare industry, providing us products from food supplements to chemical therapeutics to biological probes and beyond. Natural products from both plants and microbes have had great success in past drug discovery programs ${ }^{[1,}$ 2]. Structural novelty and biological significance are the two major innovative elements of natural products chemistry and are also key issues for drug development. The identification of natural compounds with novel structures and important biological activities, especially those possessing new carbon skeletons, has been the main challenge in the fields of natural products, organic synthesis and pharmacology. Traditional Chinese medicines (TCM) medications are proven reservoirs of novel lead structures, including the well-known examples of artemisinin (an antimalarial ${ }^{[3]}$ and huperzine A (for AD treatment $)^{[4,5]}$. China has rich medicinal plant resources, and approximately 11000 species have been documented, only approximately $30 \%$ of which have been chemically studied. We therefore view TCM plants as a promising resource for lead structures that deserve further investigation. In depth chemical and pharmacological studies of TCM plants will also

\footnotetext{
* To whom correspondence should be addressed.

E-mail jmyue@mail.shcnc.ac.cn

Received 2012-06-13 Accepted 2012-07-03
}

provide starting points for TCM development and standardization.

In the past decade, chemical studies conducted in our research group have led to the isolation more than 2700 structurally diverse compounds from 125 plants (most with applications in TCM or folk medicine), of which 650 compounds were new structures, and 63 compounds featured unprecedented carbon skeletons or possessed unique structural motifs. The biosynthetic origins of most of these compounds with new carbon skeletons or unique structural motifs were proposed. Biological tests on these isolates via collaboration with the pharmacological research groups both in our institute and in outside organizations revealed that 182 compounds were active in the tested assays, and a number of them showed significant bioactivities associated with fatal human diseases. The structural modification of a few of the most promising bioactive compounds or drug leads produced more than 400 derivatives, 58 of which showed obviously improved activity. These studies also demonstrated the structure-activity relationship of the related compound classes. The major research findings are summarized here.

\section{Structurally diverse and novel alkaloids}

Daphniphyllum alkaloids (Figure 1): The genus Daphniphyllum is mainly distributed in the southern Asia, with 10 species growing in China. Some of these species have long been used 


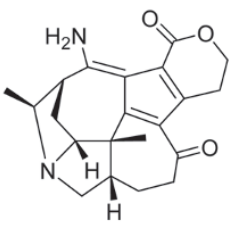

1

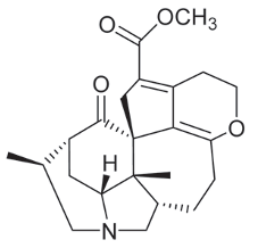

6

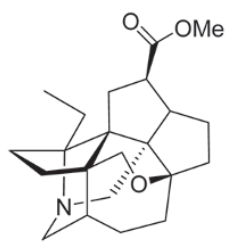

11

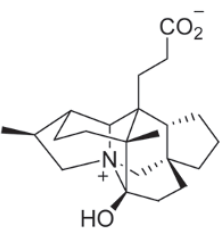

16
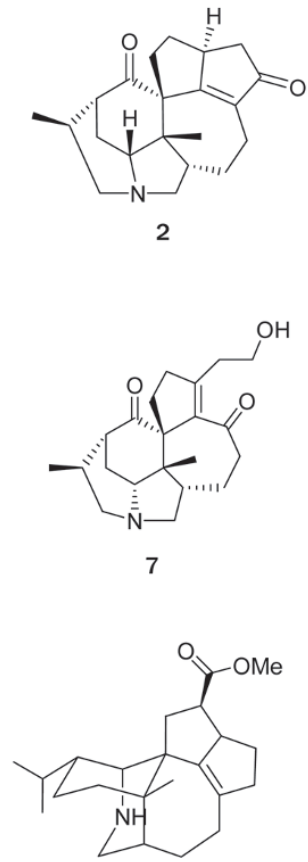

12

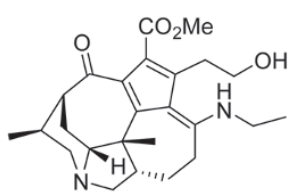

17

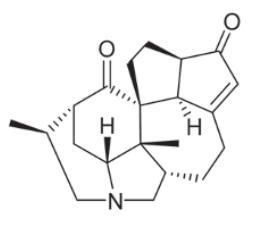

3
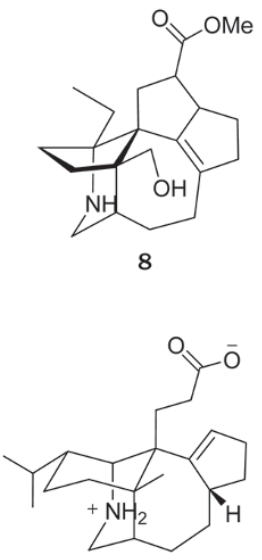

13

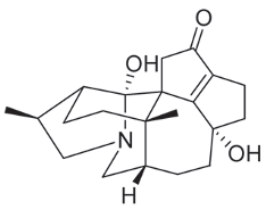

18

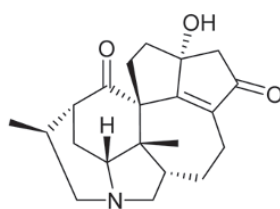

4

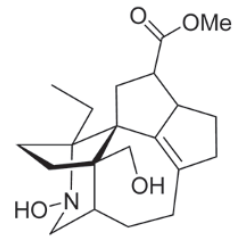

9

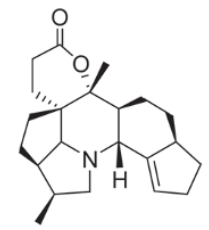

14

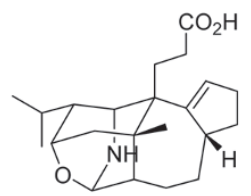

19

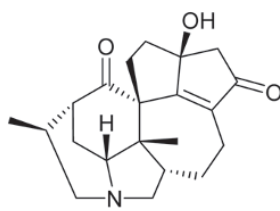

5

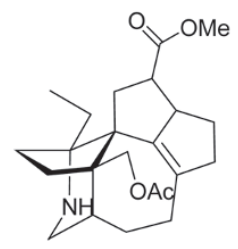

10

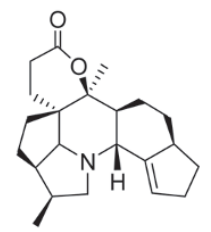

15

Figure 1. Alkaloids isolated from Daphniphyllum genus.

in TCM for the treatment of various disorders. Daphniphyllum alkaloids possessing highly complex and polycyclic features have been a challenging topic in natural products and organic synthesis. Since we published the first chemical studies on D subverticillatum in 2003, a total of 194 structurally complex alkaloids have been isolated from 9 species of Daphniphyllum in our research group, 72 of which were novel structures. Among the novel compounds, 14 of them had new skeletons or possessed rearranged carbon frameworks ${ }^{[6-21]}$. Some alkaloids showed strong cytotoxic activity ${ }^{[16]}$.

Daphnipaxinin $(\mathbf{1})^{[8]}$, the first diamino Daphniphyllum alkaloid, was isolated from $D$ paxianum. The structure of $\mathbf{1}$ was determined by spectroscopic methods, and its absolute configuration was assigned by $\mathrm{CD}$ spectrum. A series of structurally related Daphniphyllum alkaloids with an unusual degraded skeleton of C-22-noryuzurimine-type $(2-5)^{[15,16]}$ were identified from $D$ longeracemosum and $D$ yunnanense. Compound 4 showed strong cytotoxic activities, with $\mathrm{IC}_{50}$ values of 3.0 and $0.6 \mu \mathrm{mol} / \mathrm{L}$ against the tumor cell lines P388 and A549, respectively ${ }^{[16]}$. The discovery of daphnilongeranin A $(6)^{[15]}$, the first seco-10,17-longistylumphlline alkaloid from $D$ longeracemosum, suggested that the hypothetical biosynthetic route proposed for daphnicyclidine A should be reconsidered. The chemical investigation of $D$ yunnanense also afforded the first C22-nor,10,17-seco-yuzurimine-type alkaloid, daphniyunnine $\mathrm{B}(7)^{[16]}$, which represents the most degraded compound in the Daphniphyllum alkaloid class.

A series of Daphniphyllum alkaloids possessing cage-like skeletons were isolated from the seeds of $D$ paxianum ${ }^{[11]}$ and D macropodum ${ }^{[18]}$. Compounds 8-11 are the representatives of these cage-like Daphniphyllum alkaloids; in particular, paxdaphnine A (11) is the first identified 1,19-bisnorDaphniphyllum alkaloid with a highly caged skeleton and a constrained Ring-A by the formation of $\mathrm{C} 2-\mathrm{C} 8$ and $\mathrm{C} 1-\mathrm{C} 9$ bonds, whose absolute configuration was determined by $\mathrm{X}$-ray diffraction of its iodide derivative. Two structurally relevant alkaloids, paxdaphnidine A (12), bearing a unique pentacyclic framework, and paxdaphnidine B (13), possessing an uncommon tetracyclic skeleton, were isolated from the twigs and leaves of $D$ paxianum ${ }^{[9]}$. Deoxycalyciphylline B (14) and deoxyisocalyciphylline $B(15)$ were the major alkaloids with a unique fused hexacyclic skeleton from the stem of $D$ subverticillatum ${ }^{[8]}$. Their structures were assigned based on spectroscopic methods and chemical evidence, and that of $\mathbf{1 4}$ was confirmed by a single crystal X-ray diffraction determination.

Recently, angustimine (16), featuring an unprecedented 
skeleton, and angustifolimine (17), a rare diamino Daphniphyllum alkaloid, were isolated from $D$ angustifolium ${ }^{[6]}$. Calycinumines A (18) and B (19) were isolated from D calycinum ${ }^{[7]}$. Compound 18 is the first example of C-22-nor yuzuriminetype alkaloid, whose structure was confirmed by a single crystal X-ray diffraction study, and calycinumine B (19) features an unprecedented heteroatom-containing adamantane-like motif.

C,C-linked dimeric indolizidine alkaloids (Figure 2): Flueggea virosa Roxb ex Willd (Euphorbiaceae) is a TCM that has been used to treat rheumatism, pruritus, cephalic eczema, leucorrhea, and injuries. Previous chemical studies on this plant identified a number of indolizidine-type alkaloids known as Securinega alkaloids. In our recent study of this plant, two unprecedented C,C-linked dimeric indolizidine alkaloids, flueggenines A (20) and B (21), along with their precursor $(-)$-norsecurinine, were isolated from the roots of $F$ virosa $a^{[22]}$. Their structures and absolute configurations were elucidated by extensive spectroscopic analyses. The biogenetic origin of these two compounds could be traced back to the coexisting major alkaloid (-)-norsecurinine via a self-catalyzed BaylisHillman reaction as the key step to achieve the dimerization.

Other structural classes of alkaloids (Figure 2): Alkaloids are a class of structurally interesting and biologically important natural products. In the past years, we examined the chemical components of eight other plant species in the families Loganiaceae, Apocynaceae, and Lycopodiaceae, and a total of 142 structurally diversified alkaloids were isolated from the genera Gelsemium $^{[23,24]}$, Ervatamia ${ }^{[25,26]}$,Stephania ${ }^{[27,28]}$, Winchia ${ }^{[29]}$, and Lycopodium ${ }^{[30]}$, of which 42 were new compounds and 5 had novel skeletons. Some alkaloids showed strong cytotoxic activities. For example, gelseganines A-D (22-25), a new class of monoterpenoid indole alkaloids that bear an $\mathrm{N}_{4}$-iridoid unit, together with three new analogs (26-29 ${ }^{[23,24]}$ were isolated from the stems and leaves of Gelsemium elegans, a well-known toxic plant in Southeast Asia. The structures of 22-29 were determined by spectroscopic analysis, single-crystal X-ray diffraction, and chemical evidence. A plausible biogenetic pathway for alkaloids 22-25 was also postulated.

\section{Complex and novel terpenoids}

Triterpenoids (limonoids) from Meliaceae plants (Figure 3): China has a rich diversity of Meliaceae. To date, 62 species and 12 varieties of 15 genera in the Meliaceae family have been documented, and these are mainly distributed in the provinces south of the Yangtze River. Plants of this family are known to metabolize abundant nortriterpenoids (limonoids) with diverse and complex structures that have been demonstrated to have a variety of important biological activities, such as antifeeding, antibacterial, anticancer and antimalarial activities.

In the past several years, our research group made tremendous efforts to explore biologically significant chemical components from the plants in the Meliaceae family, which has led to the isolation of more than 600 structurally diverse compounds from 30 plant species. Among these, 406 were new structures, and 32 possessed previously unknown skeletons.

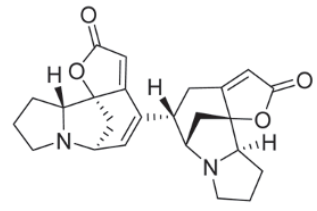

20

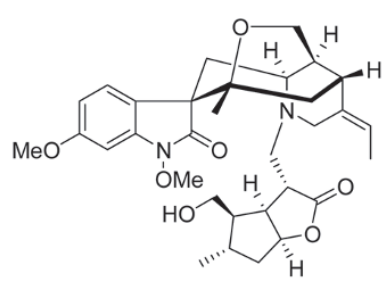

22

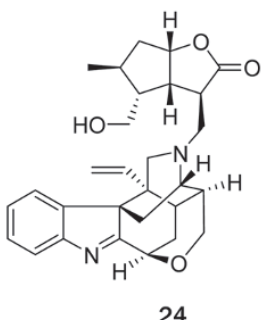

24

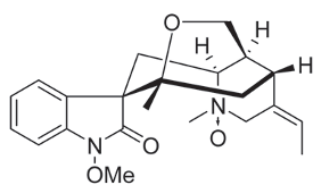

26

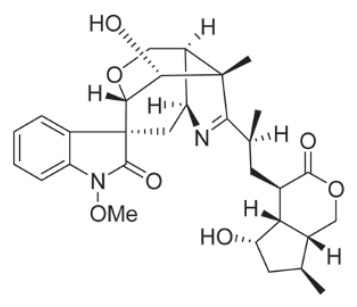

28

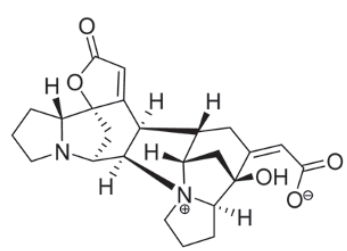

21

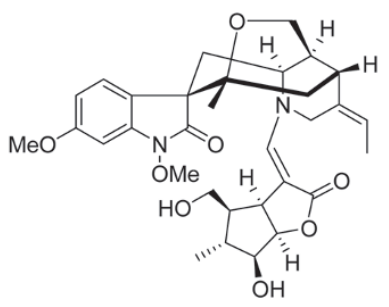

23

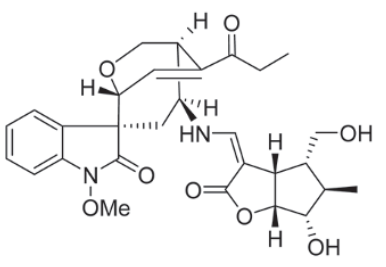

25
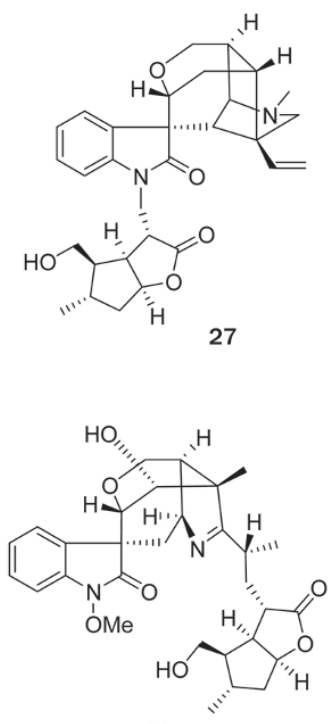

29
Figure 2. Dimeric indolizidine alkaloids and monoterpenoid indole alkaloids.

A variety of assays revealed that 50 additional compounds had important biological activities ${ }^{[31-71]}$. Our research results supported the traditional medical applications of several plants in the Meliaceae family. This is by far the most systematic and leading chemical study on the plants of the Meliaceae family worldwide. Several representative examples are summarized 


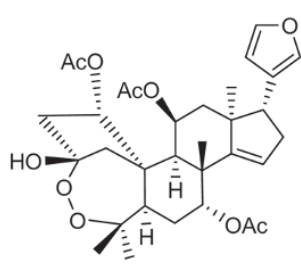

30
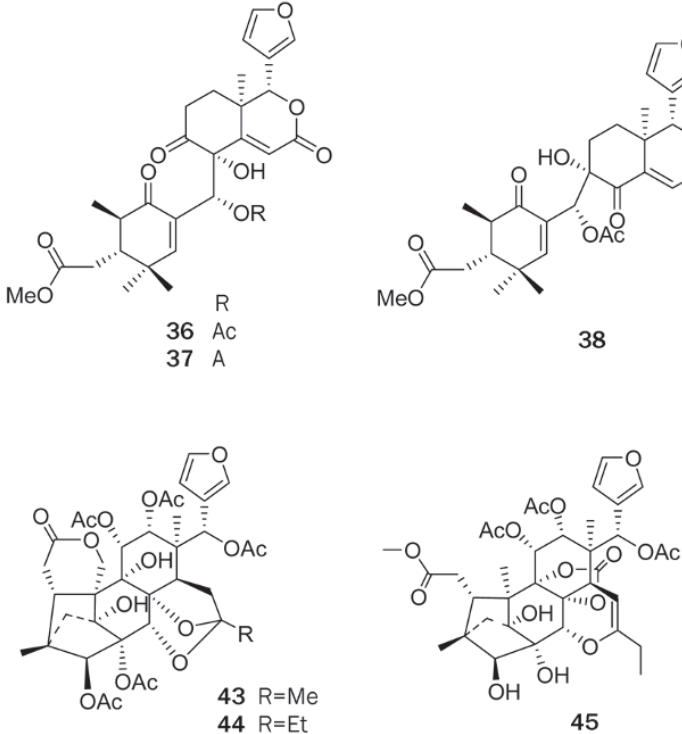

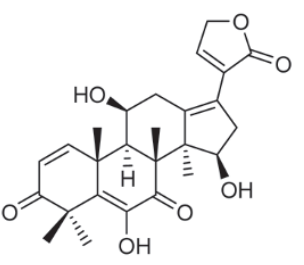

32

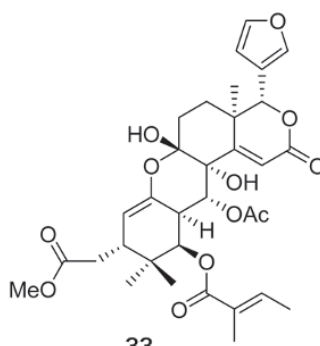

33

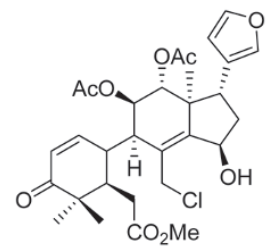

39

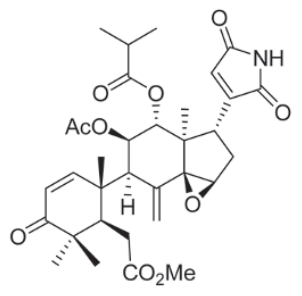

40

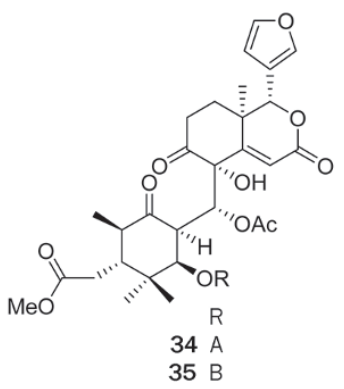

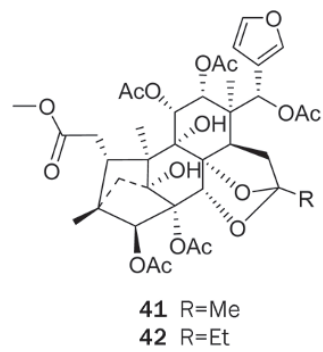

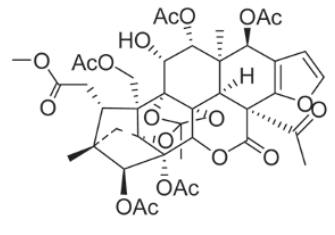

46

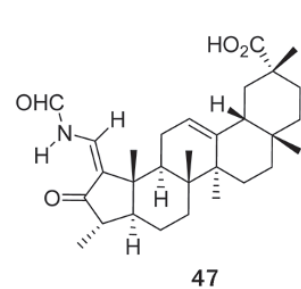

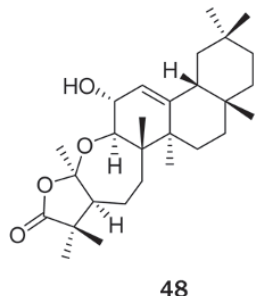

47

48

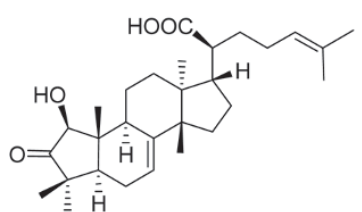

49

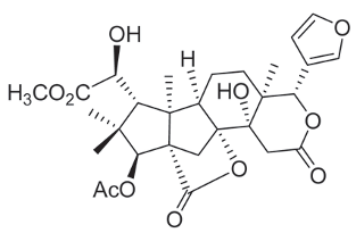

54<smiles>C#Cc1c(OC)cc2c(c1C)CC1C(C2)C2C1CC1(C)C=CC(=O)C(C)(C)C1C[C@@H]2O</smiles>

50<smiles>C#Cc1c(OC)cc2c(c1C)CC1CC2[C@@]2(C)CC[C@@H](O)C(C)(C)C2CC1=O</smiles>

51

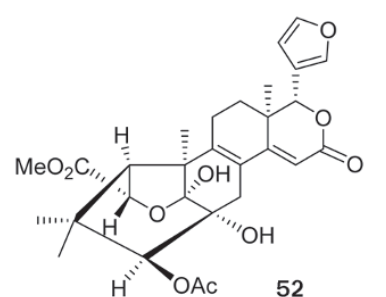

H" OAC 52

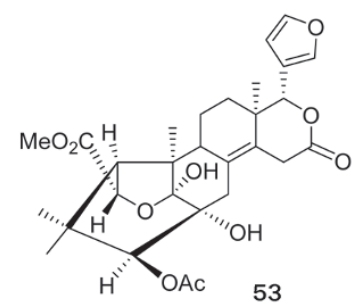

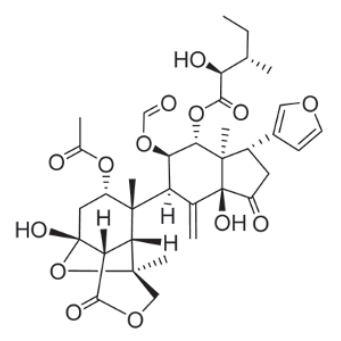

55

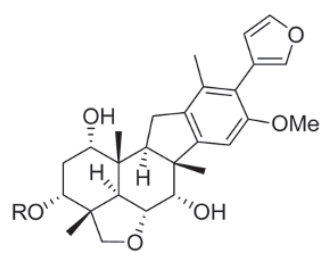

$56 \mathrm{R}=\mathrm{C}$

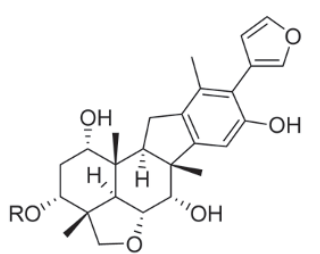

$57 \mathrm{R}=\mathrm{A}$

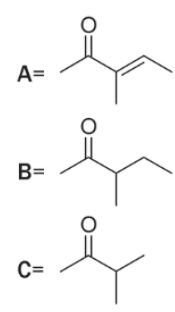

Figure 3. Triterpenoids (limonoids) isolated from Meliaceae plants.

below.

Walsuronoid A (30 $)^{[39]}$, a limonoid featuring an unprecedented 3,4-peroxide-bridged A-seco skeleton, together with walsuronoids B (31) and C (32), possessing a rare $18(13 \rightarrow 14)$-abeo-limonoid skeleton, was isolated from Walsura robusta. Their structures were elucidated by spectroscopic analysis and chemical correlation, and that of $\mathbf{3 0}$ was con- firmed by single-crystal X-ray diffraction. Compounds $\mathbf{3 1}$ and 32 showed antimalarial activities, which well matched the traditional application of this plant as a treatment for malaria.

Compounds 33-38 are 9,10-seco-tetranortriterpenoids that were discovered in the seeds of the Chinese marine mangrove plant Xylocarpus granatum ${ }^{[42,63]}$. Xylogranatin A (33) featured a unique 1,9-oxygen bridge, whose structure was confirmed by 


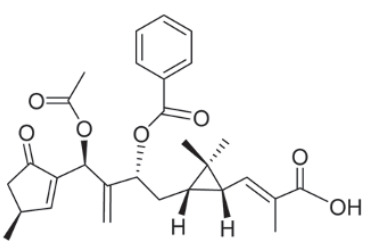

58
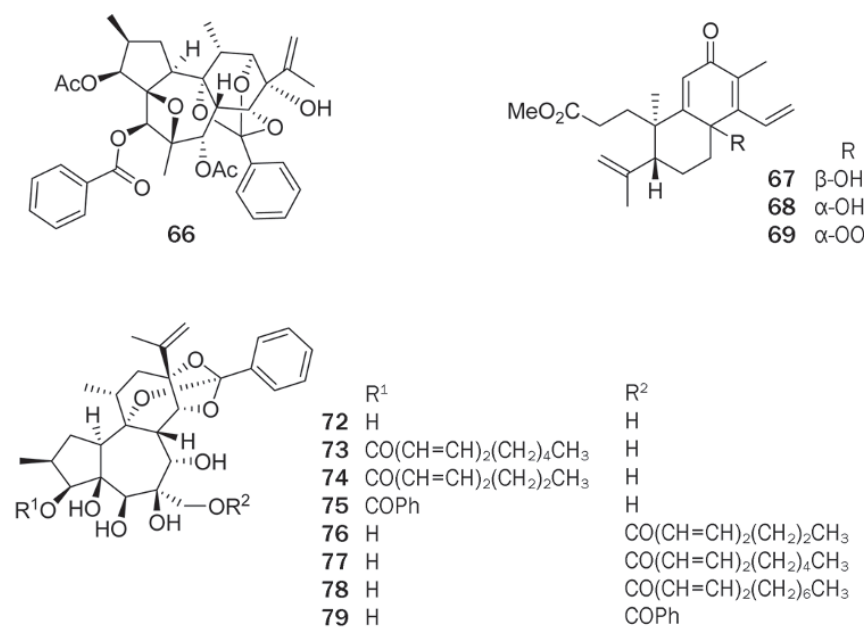

Figure 4. Structurally interesting and biologically important diterpenoids.

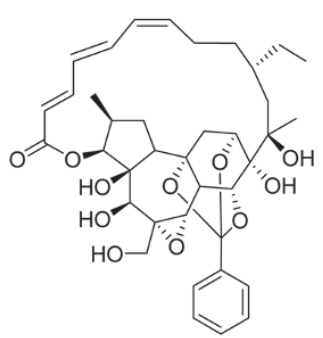

60
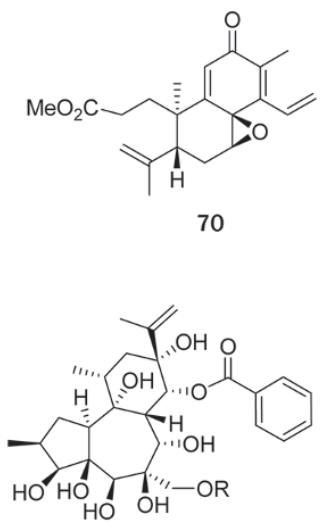

$80 \mathrm{R}$

$81 \mathrm{CO}(\mathrm{CH}=\mathrm{CH})_{2}\left(\mathrm{CH}_{2}\right)_{4} \mathrm{CH}_{3}$ $82 \mathrm{COPh}$

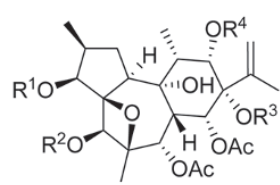

$\begin{array}{llll}R^{1} & R^{2} & R^{3} & R^{4}\end{array}$

$61 \mathrm{HH} \mathrm{Bz} \mathrm{Bz} \mathrm{Ac}$

$62 \mathrm{Ac} B z$ Bz $A C$

$63 \mathrm{H} \quad \mathrm{Bz}$ Ac $\mathrm{Bz}$

64 Ac Bz Ac Bz

65 Ac Ac Bz Ac

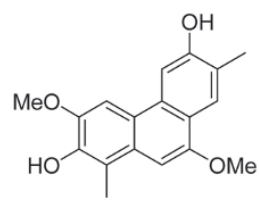

71

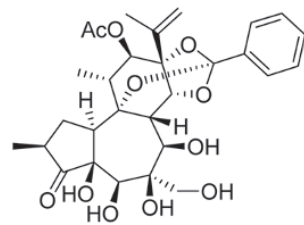

83 single-crystal X-ray diffraction, and xylogranatin D (38) furnished a novel skeleton via C-30-C-9 linkage that was postulated to arise from 36 via an $\gamma$-hydroxyl ketone rearrangement, and this pathway was chemically mimicked. Compounds 33-38 were cytotoxic to the tumor cell lines P388 and A549, with $\mathrm{IC}_{50}$ values ranging from 6.3 to $15.7 \mu \mathrm{mol} / \mathrm{L}$.

Turrapubesins A (39) and B (40) ${ }^{[41]}$, two tetranortriterpenoids representing the first examples of halogenated and maleimidebearing limonoids, respectively, were isolated from the twigs and leaves of Turraea pubescens. Their absolute configurations were determined by X-ray crystallography (39) and by CD analysis of a dihydrogenated derivative (40).

Four 16-norphragmalin-type limonoids, chuktabularins A-D $(41-44)^{[40]}$, featuring unprecedented carbon skeletons of a biosynthetically extended $\mathrm{C} 2$ or $\mathrm{C} 3$ unit at C-15 forming a unique 2,7-dioxabicyclo[2.2.1] heptane moiety, and two limonoids, chuktabrin A (45), with the unique 1,3-dioxolan-2-one and 3,4-dihydro- $2 \mathrm{H}$-pyran motifs, and chuktabrin B $(46)^{[37]}$ possessing an unprecedented polycyclic skeleton, were isolated from Chukrasia tabularis. Their structures were elucidated by spectroscopic analyses and single crystal X-ray diffraction.

The chemical investigations of Dysoxylum hainanense revealed a series of ring A modified triterpenoids among which dysoxyhainanin $\mathrm{A}(47)^{[38]}$ possessed a unique 1,3-cyclo2,3-seco A ring with a formamido-containing appendage, dysoxyhainanin $B(48)^{[38]}$ featured an unprecedented 1,2-dinor3,10:9,10-bisseco skeleton, and dysoxyhainic acid A (49) ${ }^{[52]}$ had an unprecedented 2-nor-1,3-cyclotirucallane skeleton. Four compounds, dysoxyhainanin A (47) and dysoxyhainic acids B-C, showed significant activities against four gram-positive bacteria, Staphylococcus aureus ATCC 25923, S epidermidis ATCC 12228, Micrococcus luteus ATCC 9341, and Bacillus subtilis CMCC 63501, with MICs in the range of $6.25-50 \mu \mathrm{g} / \mathrm{mL}$.

Walsucochins A (50) and B (51), with a novel carbon skeleton, were isolated from Walsura cochinchinensis ${ }^{[36]}$. Their structures, including absolute configuration, were elucidated by spectral methods. Both compounds significantly attenuated $\mathrm{H}_{2} \mathrm{O}_{2}$-induced damage in PC12 cells in a dose-dependent manner at dosages of 1,5 , and $10 \mu \mathrm{mol} / \mathrm{L}$.

A chemical study of the stems of Khaya senegalensis led to the isolation of two limonoids, namely khayalenoids A (52) and B $(53)^{[35]}$, with an unprecedented 8-oxa-tricyclo[4.3.2.0 $\left.0^{2,7}\right]$ undecane motif in the nortriterpenoid core. Their structures, with absolute configuration, were determined by spectroscopy, X-ray crystallography, and CD analysis. Recently, another limonoid with an unprecedented carbon skeleton, grandifotane A (54), was isolated from the stem bark of $K$ grandifoliola ${ }^{[34]}$. The absolute configuration of $\mathbf{5 4}$ was determined by spectroscopy, X-ray crystallography, and ECD calculations. A biogenetic route for grandifotane A (54) synthesis from a mexicanolide-type limonoid precursor, involving an enzymatic Baeyer-Villiger oxidation as the key step, was proposed.

Aphanamolide A $(55)^{[33]}$, featuring an unprecedented carbon skeleton with a C-3-C-6 bond, was isolated from the seeds of 
Aphanamixis polystachya. Its structure was established using spectroscopic methods.

Walsucochinoids A (56) and B (57) ${ }^{[32]}$, two rearranged limonoids possessing an unprecedented carbon framework, were isolated from Walsura cochinchinensis. Their absolute configurations were assigned based on a detailed examination of spectroscopic data, single crystal X-ray diffraction analysis, and $\mathrm{CD}$ experiments.

Diterpenoids (Figure 4): Diterpenoids are a class of structurally interesting and biologically important natural products that are found in many TCM plants, and some were even proven to be the active ingredients in their respective plants. More than 260 diterpenoids were obtained by our research group in the past years from the Euphorbia ${ }^{[72]}$, Trigonostemon $^{[73-79]}$, Daphne $e^{[80]}$, Pseudolarix ${ }^{[81,82]}$, Siegesbeckia ${ }^{[83]}$, Sapium ${ }^{[84]}$, and Larix ${ }^{[85]}$ genera. Among them, 122 were new compounds, and 4 possessed novel carbon scaffolds. Biological tests demonstrated that 49 compounds exhibited important biological activities in a variety of bioassays, some of which demonstrated the biological basis of the traditional applications of those plants in TCM medication.

Diterpenoids from the Euphorbiaceae family: Lathyranoic acid $A(58)^{[72]}$, the first seco-lathyrane diterpenoid with a new skeleton was isolated from the seeds of Euphorbia lathyris. Its structure was elucidated by spectroscopic analysis and chemical transformation. Lathyranoic acid A was proposed to be biosynthetically produced from the co-existing diterpenoid Euphorbia factor L11 with an enzymatic Baeyer-Villiger oxidation as the key and the committed step, and its chemical synthesis was achieved (Scheme 1).
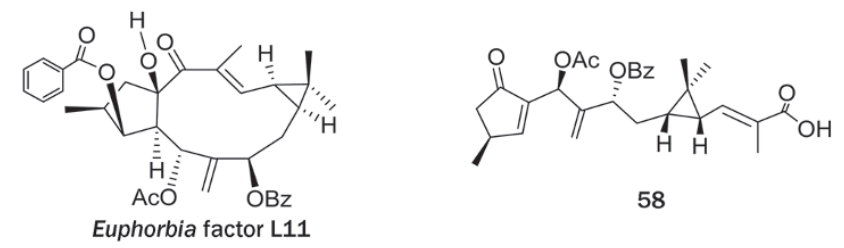

58
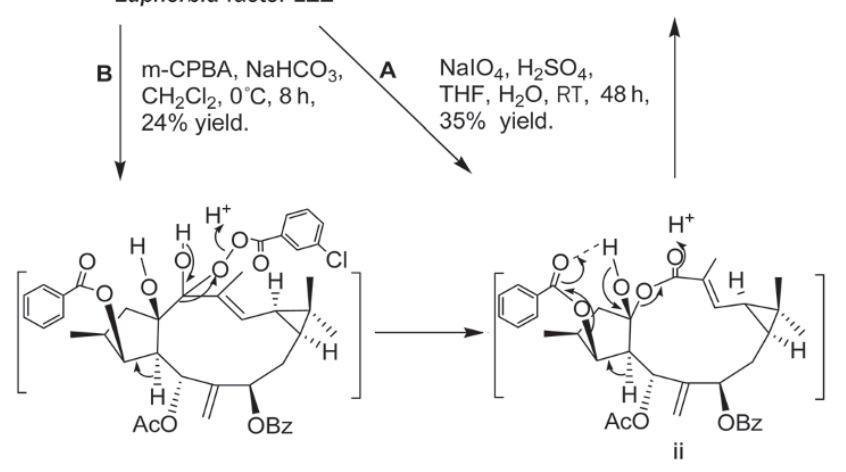

Scheme 1. Chemical transformations from Euphorbia factor L11 to 58.

Two highly modified daphnane-type diterpenoids, trigochilides A (59) and B (60), together with six highly oxygenated diterpenes, trigochinins A-I (61-66) ${ }^{[73-75]}$, were isolated from the twigs and leaves of Trigonostemon chinensis Merr collected from Yunnan Province. Trigochilides A (59) and B (60) contain 12-carbon-containing polyketide appendages, which are linked to the diterpenoid core at C-16 by a C-bond and form a macrolactone between $\mathrm{C}-1^{\prime}$ and $\mathrm{C}-3$, while trigochinins A-I (61-66) share a rare 4,6-oxetane moiety. Their structures were elucidated by spectroscopic analysis, X-ray crystallography, and CD analysis. Compounds 64 and 65 showed potent cytotoxic activities against HL-60 tumor cell lines with $\mathrm{IC}_{50}$ values of 8.1 and $6.4 \mu \mathrm{mol} / \mathrm{L}$, respectively. Compound 66 significantly inhibited MET tyrosine kinase activity $\left(\mathrm{IC}_{50}=1.95\right.$ $\mu \mathrm{mol} / \mathrm{L})$. Trigonochinenes A-E (66-71) ${ }^{[79]}$, five antibacterial diterpenoids, were isolated from the aerial parts of this plant collected from Hainan Province. Compounds 67-70 possess a rare 3,4-secocleistanthanic skeleton, and compound 71 is a highly aromatized tetranorditerpene. Compounds 67-71 were tested for antimicrobial activity against 11 microorganisms in vitro. All compounds tested were active against Helicobacter pylori-SS1, with MICs of 12.5-25 $\mu \mathrm{g} / \mathrm{mL}$, and compounds 67-70 also significantly inhibited the growth of the drug (metronidazole)-resistant strain H pylori-ATCC 43504, with MICs of $c a 50 \mu \mathrm{g} / \mathrm{mL}$. Compounds 69 and 71 also exhibited selective activities against the gram-positive bacteria Staphylococcus aureus ATCC 25923, Staphylococcus epidermidis ATCC 12228, and Micrococcus luteus ATCC 9341 with MICs in the range of $6.25-50 \mu \mathrm{g} / \mathrm{mL}$.

Twelve new highly oxygenated daphnane-type diterpenoids, genkwanines A-L (72-83) ${ }^{[80]}$, were isolated from the bud of Daphne genkwa, a well-known TCM. These compounds showed very potent cytotoxic activities against two tumor cell lines, P388 and A549, with $\mathrm{IC}_{50}$ levels of $0.15-8.40 \mu \mathrm{mol} / \mathrm{L}$. Most interestingly, three of the compounds, 75, 78, and 81, and two known compounds, yuanhuacine and yuanhuadine, strongly inhibited the endothelial cell line HMEC at the $\mathrm{IC}_{50}$ levels of 2.90-15.0 $\mu \mathrm{mol} / \mathrm{L}$.

Sesquiterpenoids: Sesquiterpenoids are the major components of many TCM plants, and they have a broad spectrum of biological activities including antiinflammatory, antiparasitic, antitumor, and anti-HIV properties. More than 18 TCM plants in the families of Chloranthaceae (four genera, Chloranthus, Sarcandra, and Hedyosmum) ${ }^{[86-95]}$ and Compositae (five genera, Eupatorium ${ }^{[96,97]}$, Vernonia ${ }^{[98]}$, Siegesbeckia, Saussurea, and Parasenecio) ${ }^{[96-101]}$, and a fungus (Lactarius piperatus) ${ }^{[102]}$, have been investigated in our laboratory, which led to the identification more than 280 compounds. Among them, 126 were new compounds, and 8 possessed new carbon skeletons. Biological activity screening revealed that 28 isolates showed important biological activities in a number of tested bioassays, and some of the results were consistent with the traditional applications of these plants in TCM.

Mono- and dimeric sesquiterpenoids (Figure 5): The Chloranthaceae family has 16 species and 5 variants belonging to three genera, Chloranthus, Sarcandra and Hedyosmum, in China. Most plants in this family have been applied in TCM and/or Chinese folk medicine for a variety of indications. Chemical studies of seven species in the Chloranthaceae family con- 


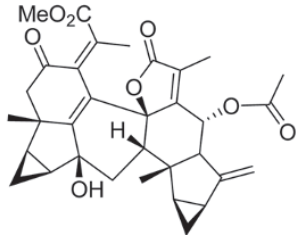

84

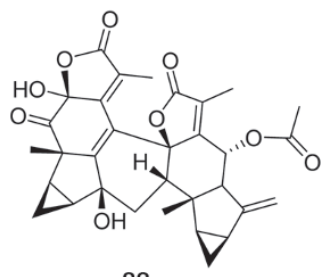

88

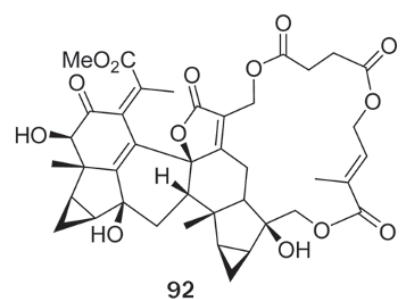

92

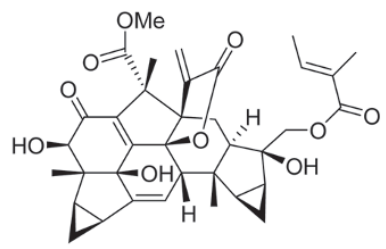

96
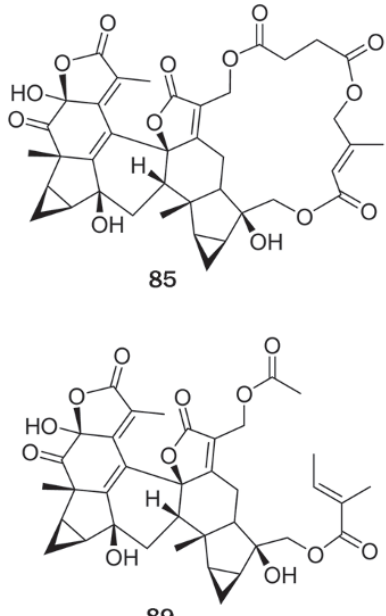

89

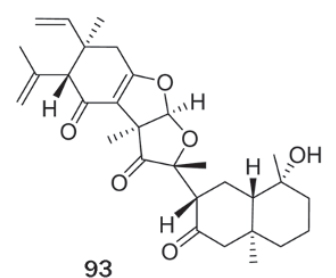

93

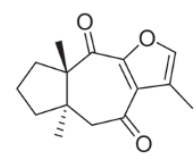

97

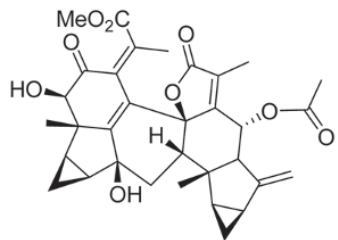

86

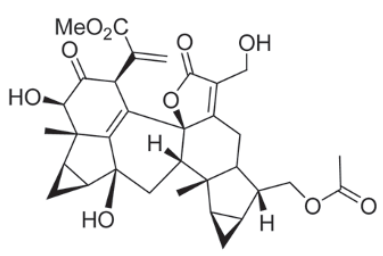

90

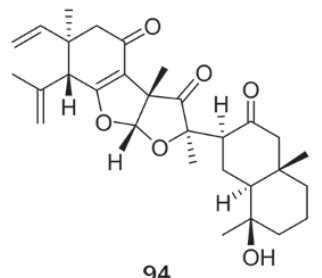

94

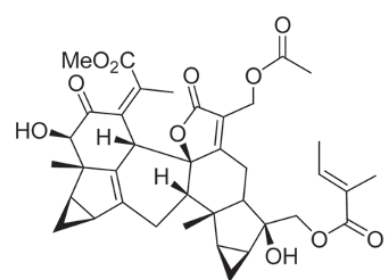

87

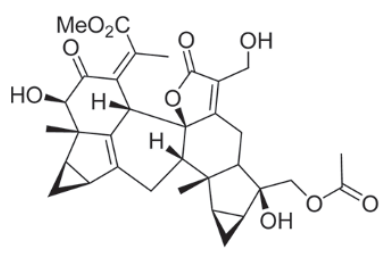

91

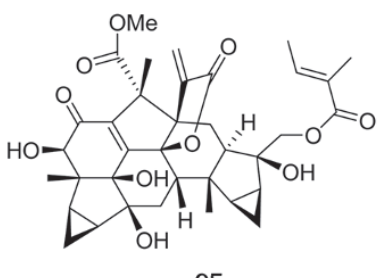

95

Figure 5. Structurally complex sesquiterpenoids.

ducted in our research group identified 42 new mono- and dimeric sesquiterpenoids, of which the sesquiterpenoid dimers are particularly interesting, especially 4 of these dimers, which possessed unprecedented carbon skeletons.

Chlorahololides A-F (84-89) ${ }^{[87,}$,8], six highly complex sesquiterpenoid dimers, were isolated from whole $C$ holostegius. Their structures and absolute configurations were established by spectroscopy, X-ray crystallography and CD analysis. Chlorahololides A-F (84-89) exhibited potent and selective inhibition of the delayed rectifier $\left(I_{\mathrm{K}}\right) \mathrm{K}^{+}$current, with $\mathrm{IC}_{50}$ values of $10.9 \pm 12.3,18.6 \pm 2.5,3.6 \pm 10.1,2.7 \pm 0.3,27.5 \pm 5.1$, and $57.5 \pm 6.1 \mu \mathrm{mol} / \mathrm{L}$, respectively. It is noteworthy that the activities of chlorahololides A-F (84-89) are 18- to 388-fold more potent than the positive control tetraethylammonium chloride $\left(\mathrm{IC}_{50}=1.05 \pm 0.21 \mathrm{mmol} / \mathrm{L}\right)$, a classical blocker of the delayed rectifier $\mathrm{K}^{+}$current. Three more sesquiterpenoid dimers, multistalides A-B and chloramultilide A (90-92), were isolated from whole $C$ multistachys ${ }^{[90,91]}$. Serratustones A (93) and B (94), which share an unprecedented carbon skeleton representing a novel dimerization of an elemane and a eudesmane sesquiterpenoid, were isolated from $C$ serratus $^{[86]}$. Two novel lindenane-type sesquiterpenoid dimers, sarcanolides A (95) and B (96), featuring an unprecedented carbon framework via the formation of C-11-C-7' bond, were isolated from whole $S$ hainanensis ${ }^{[92]}$. The structures of compounds 93-96, including the absolute configuration were fully determined by spectroscopy, X-ray crystallography, and CD analysis in combination with ECD calculation. A number of novel sesquiterpenoids were also isolated from plants in the Chloranthaceae family; eg, hlorantene A (97) isolated from C serratus possessed a unique C-4 to C-10 linkage ${ }^{[89]}$.

Phloroglucinol-coupled sesquiterpenoids (Figure 5): Eucalyptus globulus Labill, a tall timber tree, grows widely in the southern part of China. Its fruits and leaves have been used as a Chinese folk medicine to treat flu, dysentery, eczema, and scald. A large number of phloroglucinol-coupled sesquiterpenoids and other classes of phloroglucinol-coupled compounds were isolated from E globulus and other species in the Eucalyptus genus. Of these, eucalyptals A-C (98-100) $)^{[94]}$, with a novel 3,5-diformyl-isopentyl phloroglucinol-coupled cadinane 
carbon framework, were isolated from the fruits of $E$ globulus. Their structures were elucidated by spectroscopic analysis, and that of 98 was confirmed by single-crystal X-ray diffraction. Compounds $\mathbf{9 8 - 1 0 0 ~ s h o w e d ~ s e l e c t i v e ~ a c t i v i t y ~ a g a i n s t ~}$ HL-60, with $\mathrm{IC}_{50}$ values of $1.7,6.8$, and $17 \mu \mathrm{mol} / \mathrm{L}$, respectively.

\section{Miscellaneous}

In addition to our particular interests in natural alkaloids and terpenoids (tri, di, and sesquiterpenoids), we isolated more than 300 phenolics and prenylated polyketides from approximately 20 TCM or herb plants. Among them, approximately 60 were new compounds, and 6 had new carbon skeletons (Figure 6). In particular, 48 of these compounds showed significant biological activities in a variety of bioassays and provided a scientific foundation for the use of a number of traditional Chinese herbs ${ }^{[103-114]}$.

A series of phenolic compounds were isolated from the ethanolic extract of whole Sarcostemma acidum. Sacidumlignan $D(\mathbf{1 0 1})^{[108]}$ was found to have an unprecedented rearranged tetrahydrofuran lignan skeleton. Psoracorylifols A-E (102-106 $)^{[105]}$ represented five novel compounds from buguzhi, a well-known TCM made from the seeds of Psoralea corylifolia. The structure of $\mathbf{1 0 2}$ was confirmed by single-crystal X-ray diffraction. Psoracorylifols D and E (105 and 106) exhibit an unprecedented carbon skeleton. A plausible biogenetic origin of psoracorylifols A-E (102-106) was also postulated. Psoracorylifols A-E (102-106) showed significant inhibition against two strains of H pylori (SS1 and ATCC 43504), with
MICs of 12.5-25 $\mu \mathrm{g} / \mathrm{mL}$, respectively. Notably, the activity of psoracorylifols A-E (102-106) are 5-10 times stronger than that of metronidazole against $H$ pylori ATCC 43504, a drug (metronidazole)-resistant strain; metronidazole is a critical ingredient in combination therapies of $H$ pylori infection. The chemical investigation of the seeds of Psoralea corylifolia also revealed a number of prenylflavonoids, among which the two new compounds, corylifols A and B (107 and 108) ${ }^{[107]}$, significantly inhibited two hospital pathogenic gram-positive bacteria, S aureus ATCC 25923 (MICs: 0.147 and $0.037 \mathrm{mmol} / \mathrm{L}$ ) and $S$ epidermidis ATCC 12228 (MICs: 0.147 and $0.037 \mathrm{mmol} / \mathrm{L}$ ) in vitro. Cinnacassides A-E (109-113) ${ }^{[103]}$ are five novel glycosides with a unique geranylphenylacetate aglycone carbon skeleton from a common TCM (Rougui) based on the stem bark of Cinnamomum cassia. Each of the cinnacassides A-D (109-113) possessed one of the four stereoisomers of the aglycone. Their structures were established by extensive spectroscopic analysis and chemical and chiroptical methods. Plausible biosynthetic routes for 109-113 were also proposed.

Harrisotones A-E (114-118), five novel prenylated polyketides with a rare spirocyclic hydroperoxypolyketidederived skeleton, along with the new hydroperoxypolyketide harrisonol A (119), were isolated from Harrisonia perforate ${ }^{[104]}$. Their structures were extensively elucidated through spectroscopic analysis and CD spectra. The origins of compounds 114-118 could be traced back to harrisonol A (119). Harrisotone $A$ and $C$ and harrisonol $A(\mathbf{1 1 4}, 116$, and 119) exhibited significant cytotoxic activity against P388 tumor cells, with $\mathrm{IC}_{50}$ values of $1.56,2.35$, and $0.27 \mu \mathrm{mol} / \mathrm{L}$, respectively. Har-<smiles>COc1cc([C@]2(c3cc(OC)c(O)c(OC)c3)OCC(C)[C@H]2C)cc([O-])c1O</smiles>

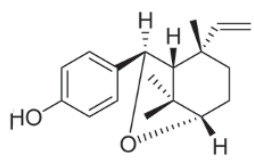

106

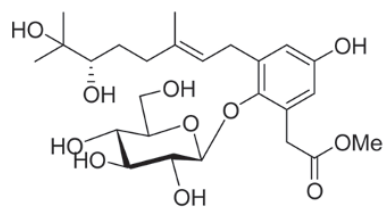

$11314 S$<smiles>C=CC1CCC(C(=C)C)OC1(O)c1ccc(O)cc1</smiles>

102

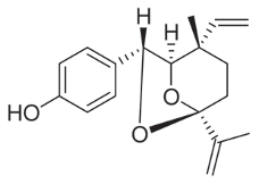

103

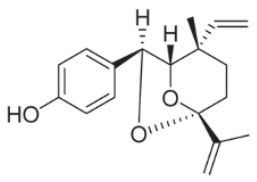

104

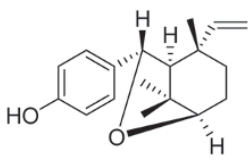

105<smiles>CC(C)=CCc1c(O)ccc(C(=O)/C=C/c2ccc(O)c(O)c2)c1O</smiles>

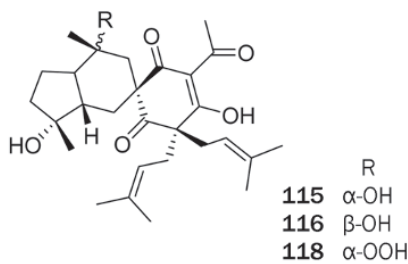

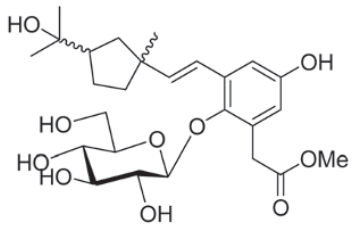

109 11S, 14S 111 11S, 14R 110 11R, 14S 112 11R, 14S

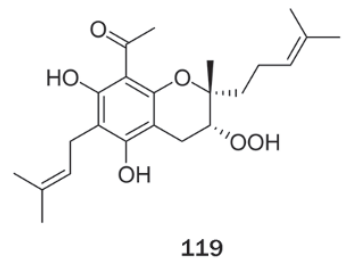

Figure 6. Phenolics and prenylated polyketides. 
risotone A (114) and harrisonol A (119) also showed moderate activity against $\mathrm{A} 549$ tumor cells, with $\mathrm{IC}_{50}$ values of 24.5 and $26.6 \mu \mathrm{mol} / \mathrm{L}$, respectively.

\section{Structural modifications and structure-activity relation- ship studies}

In our search for bioactive natural products $[13,16,22,24,25,29,33,36$, $38,39,41,42,44-46,51-53,58,63,68,70,73-81,85,87-88,93,95-98,103-109,115-120]$, a large number of compounds were found to exhibit a variety of biological activities, and 11 compounds with particularly promising potential were selected for structure optimization and structure-activity relationship studies. As a result, over 400 new derivatives were obtained. Among these derivatives, 58 showed significantly improved activities, which provided opportunities to explore the structure-activity relationship of the related compound class ${ }^{[121-125]}$. As an example, we will discuss the structure optimization and structure-activity relationship study of the antiangiogenesis pseudolaric acid $\mathrm{B}$ $(\mathrm{PAB})^{[121]}$. PAB is the major active component of a well-known TCM (Tujinpi), the root bark of Pseudolarix kaempferi, which has traditional applications as an antifungal and abortifacient for use in the early stage of pregnancy. PAB also showed strong cytotoxic activity. In our collaboration study, this compound was found for the first time to have strong antiangiogenic activity with a unique mode of antitumor action ${ }^{[118-120]}$. A structural modification of PAB was thus conducted, and more than 40 derivatives were prepared in the first round. Antitumor assays showed that nine derivatives in the series 120a-120n showed significantly improved activities, while those in the 121a-121d and 122a-122g series were inactive.
Observation of the structures of $\mathrm{PAB}$ and its derivatives revealed a clear antitumor structure activity relationship (Scheme 2) ${ }^{[121]}$ : (1) All of the active PAB compounds tested in our study (120a-120n) have amphipathic properties and possess a hydrophobic domain of a constrained-rings system and a hydrophilic domain consisting of a side chain possessing an conjugated double bond and a terminal carboxylic acid. (2) A hydrophobic group $\mathrm{R}^{1}$ at $\mathrm{C}-7$ and a $\Delta^{7}$ double bond are necessary for the anticancer activity, and the bulk and steric factor of $\mathrm{R}^{1}$ also seem relevant to the activity. (3) The chain length and/or the conjugated double bonds in the side chain are essential for the anticancer activity. (4) Any structural changes in the seven-membered ring, $e g, \Delta^{7}$ double bond migration and oxygenation at C-7 or C-8, will render the analogs inactive. (5) The C-4 acetoxyl group is crucial for the activity and its removal or replacement with a bulk acyloxy group significantly attenuated the activity. (6) The free carboxylic acid group in the terminus of the side chain is necessary for the anticancer activity, while acylation or amidation of this group with either a hydrophilic or a hydrophobic group is detrimental to the activity.

PAB is also a strong antifungal agent. The anticancer SAR of the aforementioned PAB analogs is very similar to the antifungal SAR reported by our group ${ }^{[81]}$, except for the difference in the modification of the $R^{1}$ group. The modification of the $\mathrm{R}^{1}$ group of $\mathrm{PAB}$ showed a particularly exciting result with respect to anticancer activity. Meanwhile, in an antifungal assay, all of the structurally modified PAB analogs showed attenuated activities or were completely inactive ${ }^{[81]}$. Our studies suggest that $\mathrm{PAB}$ is very promising as an anticancer drug
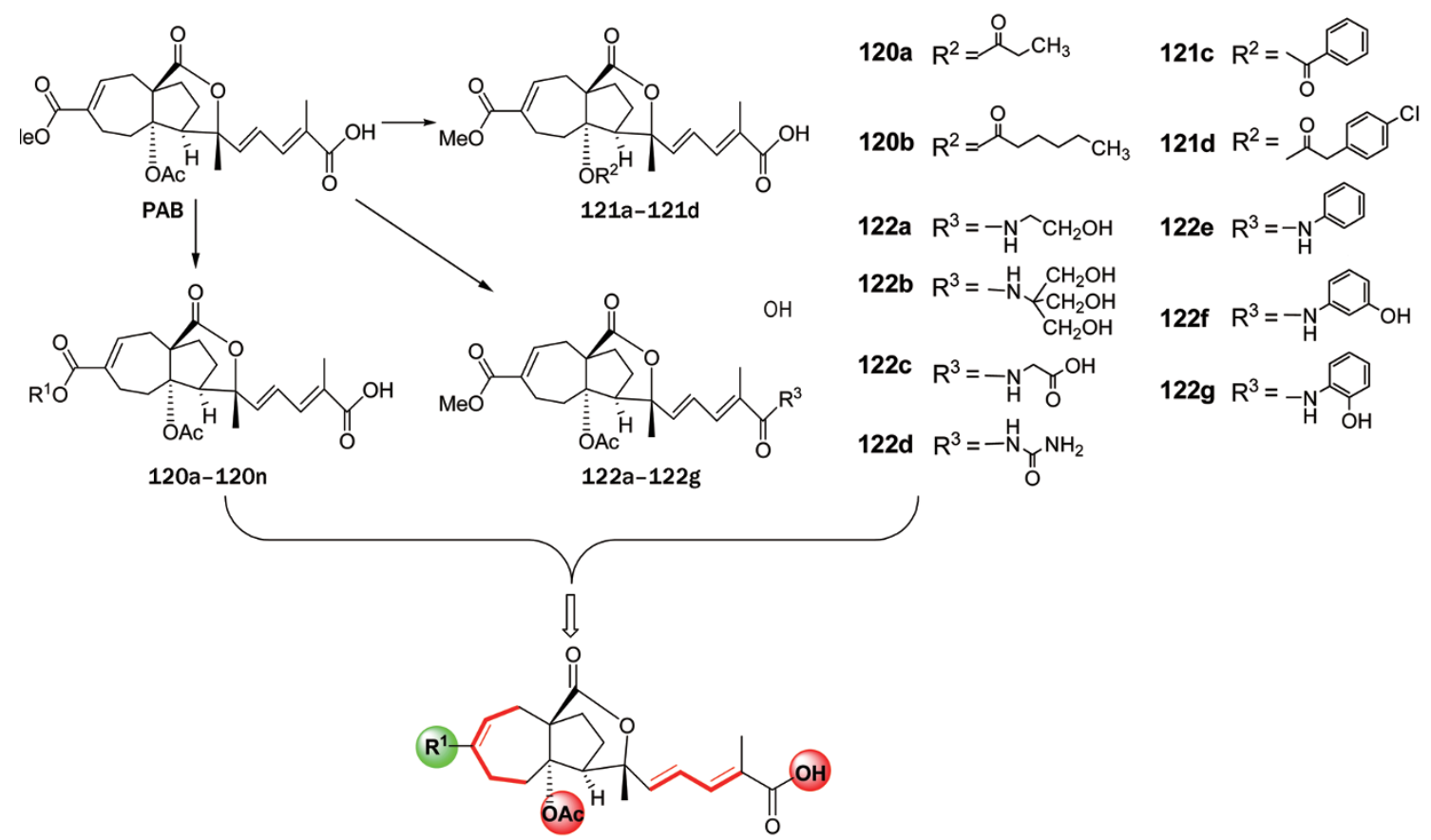

Green: Modification with hydrophobic $\mathrm{R}^{1}$ is allowed Red: Modification is forbidden

Scheme 2. Preparation of PAB derivatives and structure activity relationship study. 
lead but limited as an antifungal lead due to its loss of activity upon modification and strong cytotoxic side effects.

\section{Acknowledgements}

This work was supported by the National Science \& Technology Major Project "Key New Drug Creation and Manufacturing Program" (Grant № 2011ZX09307-002-03), the foundation of the Ministry of Science and Technology (2012CB721105) of China, and the National Natural Science Foundation (Grant № 30025044, 30630072, and 21072203) of China.

\section{References}

1 Newman DJ, Cragg GM. Natural products as sources of new drugs over the last 25 years. J Nat Prod 2007; 70: 461-77.

2 Newman DJ, Cragg GM, Snader KM. Natural products as sources of new drugs over the period 1981-2002. J Nat Prod 2003; 66: 1022-37.

$3 \mathrm{Li} \mathrm{Y,} \mathrm{Wu} \mathrm{YL.} \mathrm{Advances} \mathrm{in} \mathrm{medicinal} \mathrm{chemistry} \mathrm{and} \mathrm{pharmacology}$ of artemisinin and its derivatives; Chapter 11. In: Bai DL, Chen $\mathrm{KX}$, editors. Progress in chemistry series advances in medicinal chemistry. Beijing: Chemical Industry Press; 2004. p 433-503.

4 Liu JS, Zhu YL, Yu CM, Zhou YZ, Han YY, Wu FW, et al. The structures of huperzine $A$ and $B$, two new alkaloids exhibiting marked anticholinesterase activity. Can J Chem 1986; 64: 837-9.

5 Xu ZL, Chu BM, Luan XH, Wu WZ, Cai DG. The structural identification of fordine. Med J Chin PLA 1985; 10: 263-4.

6 Zhang CR, Fan CQ, Dong SH, Liu HB, Zhou WB, Wu Y, et al. Angustimine and angustifolimine: two new alkaloids from Daphniphyllum angustifolium. Org Lett 2011; 13: 2440-3.

7 Zhang CR, Liu HB, Dong SH, Zhu JY, Wu Y, Yue JM. Calycinumines A and B, two novel alkaloids from Daphniphyllum calycinum. Org Lett 2009; 11: 4692-5.

8 Yang SP, Yue JM. First diamino Daphniphyllum alkaloid, daphnipaxinin, with an unprecedented heterohexacyclic skeleton from Daphniphyllum paxianum. Org Lett 2004; 6: 1401-4.

9 Zhan ZJ, Yang SP, Yue JM. Paxdaphnidines A and B, novel pentaand tetracyclic alkaloids from Daphniphyllum paxianum. J Org Chem 2004; 69: 1726-9.

10 Yang SP, Yue JM. Two novel alkaloids with a unique fused hexacycylic skeleton from Daphniphyllum subverticillatum. J Org Chem 2003; 68: 7961-6.

11 Fan CQ, Yin S, Xue JJ, Yue JM. Novel alkaloids, paxdaphnines A and B with unprecedented skeletons from the seeds of Daphniphyllum paxianum. Tetrahedron 2007; 63: 115-9.

12 Zhan ZJ, Zhang CR, Yue JM. Caldaphnidines A-F, six new Daphniphyllum alkaloids from Daphniphyllum calycinum. Tetrahedron 2005; 61: 11038-45.

13 Zhang CR, Liu HB, Feng T, Zhu JY, Geng MY, Yue JM. Alkaloids from the leaves of Daphniphyllum subverticillatum. J Nat Prod 2009; 72 : 1669-72.

14 Zhang CR, Yang SP, Yue JM. Alkaloids from the twigs of Daphniphyllum calycinum. J Nat Prod 2008; 71: 1663-8.

15 Yang SP, Zhang H, Zhang CR, Chen HD, Yue JM. Alkaloids from Daphniphyllum longeracemosum. J Nat Prod 2006; 69: 79-82.

16 Zhang $\mathrm{H}$, Yang SP, Fan CQ, Ding J, Yue JM. Daphniyunnines A-E, alkaloids from Daphniphyllum yunnanense. J Nat Prod 2006; 69: 553-7.

17 Gan LS, Wang XN, Fan CQ, Wu Y, Yue JM. Alkaloids from fruits of Daphniphyllum oldhamii. Helv Chim Acta 2007; 90: 2395-400.

18 Wang XN, Gan LS, Fan CQ, Yin S, Yue JM. Alkaloids from the fruits of
Daphniphyllum macropodum. Helv Chim Acta 2007; 90: 2156-62.

19 Yang SP, Yue JM. Alkaloids from Daphniphyllum longeracemosum. Helv Chim Acta 2006; 89: 2783-8.

20 Chen X, Zhan ZJ, Yue JM. Longistylumphyllines A-C, three new alkaloids from Daphniphyllum longistylum. Helv Chim Acta 2005; 88: 854-60.

21 Chen X, Zhan ZJ, Yue JM. Oldhamiphylline A: a novel hexacyclic alkaloid from Daphniphyllum oldhami. Chem Biodivers 2004; 1: 1513-8.

22 Gan LS, Fan CQ, Yang SP, Wu Y, Lin LP, Ding J, et al. Flueggenines $\mathrm{A}$ and $\mathrm{B}$, two novel $\mathrm{C}, \mathrm{C}$-linked dimeric indolizidine alkaloids from Flueggea virosa. Org Lett 2006; 8: 2285-8.

23 Yin S, He XF, Wu Y, Yue JM. Monoterpenoid indole alkaloids bearing an $N_{4}$-iridoid from Gelsemium elegans. Chem Asian J 2008; 3 : 1824-9.

24 Xu YK, Yang SP, Liao SG, Zhang H, Lin LP, Ding J, et al. Alkaloids from Gelsemium elegans. J Nat Prod 2006; 69: 1347-50.

25 Zhang H, Wang XN, Lin LP, Ding J, Yue JM. Indole alkaloids from three species of the Ervatamia genus: $E$ officinalis, $E$ divaricata, and E divaricata Gouyahua. J Nat Prod 2007; 70: 54-9.

26 Zhang $\mathrm{H}$, Yue JM. Indole alkaloids from the whole plants of Ervatamia officinalis. Helv Chim Acta 2005; 88: 2537-42.

27 Zhang H, Yue JM. Hasubanan type alkaloids from Stephania longa. J Nat Prod 2005; 68: 1201-7.

28 Zhang $\mathrm{H}$, Yue JM. New stephaoxocane alkaloids from Stephania longa. Helv Chim Acta 2006; 89: 1105-9.

29 Gan LS, Yang SP, Wu Y, Ding J, Yue JM. Terpenoid indole alkaloids from Winchia calophylla. J Nat Prod 2006; 69: 18-22.

30 Yin S, Fan CQ, Wang XN, Yue JM. Lycodine-type alkaloids from Lycopodium casuarinoides. Helv Chim Acta 2006; 89: 138-43.

31 Liao SG, Chen HD, Yue JM. Plant orthoesters. Chem Rev 2009; 109: 1092-140.

32 Han ML, Zhang H, Yang SP, Yue JM. Walsucochinoids A and B: new rearranged limonoids from Walsura cochinchinensis. Org Lett 2012; 14: 486-9.

33 Yang SP, Chen HD, Liao SG, Xie BJ, Miao ZH, Yue JM. Aphanamolide A, a new limonoid from Aphanamixis polystachya. Org Lett 2011; 13 : 150-3.

34 Yuan T, Zhu RX, Zhang H, Odeku OA, Yang SP, Liao SG, et al. Structure determination of grandifotane a from Khaya grandifoliola by NMR, X-ray diffraction, and ECD calculation. Org Lett 2010; 12: 252-5.

35 Yuan T, Yang SP, Zhang CR, Zhang S, Yue JM. Two limonoids, khayalenoids $A$ and $B$ with an unprecedented 8-oxa-tricyclo[4.3.2.0.7.7] undecane motif from Khaya senegalensis. Org Lett 2009; 11: 61720.

36 Zhou ZW, Yin S, Zhang HY, Fu Y, Yang SP, Wang XN, et al. Walsucochins $A$ and $B$ with an unprecedented skeleton isolated from Walsura cochinchinensis. Org Lett 2008; 10: 465-8.

37 Zhang CR, Fan CQ, Zhang L, Yang SP, Wu Y, Lu Y, et al. Chuktabrins $A$ and $B$, two novel limonoids from the twigs and leaves of Chukrasia tabularis. Org Lett 2008; 10: 3183-6.

38 He XF, Wang XN, Gan LS, Yin S, Dong L, Yue JM. Two novel triterpenoids from Dysoxylum hainanense. Org Lett 2008; 10: 4327-30.

39 Yin S, Wang XN, Fan CQ, Liao SG, Yue JM. The first limonoid peroxide in the meliaceae family: walsuronoid a from Walsura robusta. Org Lett 2007; 9: 2353-6.

40 Zhang CR, Yang SP, Liao SG, Fan CQ, Wu Y, Yue JM. Chuktabularins A-D, four new limonoids with unprecedented carbon skeletons from the stem bark of Chukrasia tabularis. Org Lett 2007; 9: 3383-6.

41 Wang XN, Yin S, Fan CQ, Wang FD, Lin LP, Ding J, et al. Turrapubesins 
$A$ and $B$, first examples of halogenated and maleimide-bearing limonoids in nature from Turraea pubescens. Org Lett 2006; 8: 3845-8.

42 Yin S, Fan CQ, Wang XN, Lin LP, Ding J, Yue JM. Xylogranatins A-D: novel tetranortriterpenoids with an unusual 9,10-seco scaffold from marine mangrove Xylocarpus granatum. Org Lett 2006; 8: 4935-8.

43 Fan CQ, Wang XN, Yin S, Zhang CR, Wang FD, Yue JM. Tabularisins $A-D$, phragmalin ortho esters with new skeleton isolated from the seeds of Chukrasia tabularis. Tetrahedron 2007; 63: 6741-7.

44 Wang XN, Yin S, Fan CQ, Lin LP, Ding J, Yue JM. Eight new limonoids from Turraea pubescens. Tetrahedron 2007; 63: 8234-41.

45 Liu J, Yang SP, Su ZS, Lin BD, Wu Y, Yue JM. Limonoids from the stems of Toona ciliata var henryi (Meliaceae). Phytochemistry 2011; 72: 2189-96.

46 Lin BD, Chen HD, Liu J, Zhang S, Wu Y, Dong L, et al. Mulavanins A-E: limonoids from Munronia delavayi. Phytochemistry 2010; 71: 1596-601.

47 Zhang B, Yang SP, Yin S, Zhang CR, Wu Y, Yue JM. Limonoids from Khaya ivorensis. Phytochemistry 2009; 70: 1305-8.

48 Xie BJ, Yang SP, Yue JM. Terpenoids from Dysoxylum densiflorum. Phytochemistry 2008; 69: 2993-7.

49 Zhang $\mathrm{H}$, Odeku QA, Wang XN, Yue JM. Limonoids from the stem bark of Khaya grandifoliola. Phytochemistry 2008; 69: 271-5.

50 Wang XN, Fan CQ, Yin S, Gan LS, Yue JM. Structural elucidation of limonoids and steroids from Trichilia connaroides. Phytochemistry 2008; 69: 1319-27.

51 Liu HB, Zhang H, Li P, Wu Y, Gao ZB, Yue JM. Kv1.2 potassium channel inhibitors from Chukrasia tabularis. Org Biomol Chem 2012, 10: $1448-58$.

52 He XF, Wang XN, Ying S, Dong L, Yue JM. Ring A modified novel triterpenoids from Dysoxylum hainanense. Eur J Org Chem 2009; 28: 4818-24.

53 Dong SH, Zhang CR, Dong L, Wu Y, Yue JM. Onoceranoid-type triterpenoids from Lansium domesticum. J Nat Prod 2011; 74: 1042-8.

54 Yuan T, Zhang CR, Yang SP, Yue JM. Limonoids and triterpenoids from Khaya senegalensis. J Nat Prod 2010; 73: 669-74.

55 Dong SH, Zhang CR, He XF, Liu HB, Wu Y, Yue JM. Mesendanins A-J, limonoids from the leaves and twigs of Melia toosendan. J Nat Prod 2010; 73: 1344-9.

56 Lin BD, Zhang CR, Yang SP, Zhang S, Wu Y, Yue JM. D-ring-opened phragmalin-type limonoid orthoesters from the twigs of Swietenia macrophylla. J Nat Prod 2009; 72: 1305-13.

57 Lin BD, Yuan T, Zhang CR, Dong L, Zhang B, Wu Y, et al. Structurally diverse limonoids from the fruits of Swietenia mahagoni. J Nat Prod 2009; 72: 2084-90.

58 Chen HD, Yang SP, Wu Y, Dong L, Yue JM. Terpenoids from Toona ciliata. J Nat Prod 2009; 72: 685-9.

59 Chen HD, Yang SP, Liao SG, Zhang B, Wu Y, Yue JM. Limonoids and sesquiterpenoids from Amoora tsangii. J Nat Prod 2008; 71: 93-7.

60 Xie BJ, Yang SP, Chen HD, Yue JM. Agladupols A-E, triterpenoids from Aglaia duperreana. J Nat Prod 2007; 70: 1532-5.

61 Zhang CR, Yang SP, Zhu Q, Liao SG, Wu Y, Yue JM. Nortriterpenoids from Chukrasia tabularis var. velutina. J Nat Prod 2007; 70: 16169.

62 Liao SG, Yang SP, Yuan T, Zhang CR, Chen HD, Wu Y, et al. Limonoids from the leaves and stems of Toona ciliate. J Nat Prod 2007; 70: 1268-73.

63 Yin S, Wang XN, Fan CQ, Lin LP, Ding J, Yue JM. Limonoids from the seeds of the marine mangrove Xylocarpus granatum. J Nat Prod 2007; 70: 682-5.

64 Gan LS, Wang XN, Wu Y, Yue JM. Tetranortriterpenoids from Cipa- dessa baccifera. J Nat Prod 2007; 70: 1344-7.

65 Chen YY, Wang XN, Fan CQ, Yin S, Yue JM. Swiemahogins A and B, two novel limonoids from Swietenia mahogany. Tetrahedron Lett 2007; 48: 7480-4.

66 Wang XN, Fan CQ, Yue JM. New pregnane steroids from Turraea pubescens. Steroids 2006; 71: 720-4.

67 He XF, Wang XN, Ying S, Dong L, Yue JM. Ring A-seco triterpenoids with antibacterial activity from Dysoxylum hainanense. Bioorg Med Chem Lett 2011; 21: 125-9.

68 Zhang F, Liao SG, Zhang CR, He XF, Chen WS, Yue JM. Limonoids and diterpenoids from Toona ciliata Roem var yuunanensis. Planta Med 2011; 77: 1617-22.

69 Lin BD, Zhang CR, Yang SP, Wu Y, Yue JM. Phragmalin-type linomoid orthoesters from the twigs of Swietenia macrophylla. Chem Pharm Bull 2011; 59: 458-65.

70 Zhang CR, Yang SP, Chen XQ, Wu Y, Zhen XC, Yue JM. Limonoids from the twigs and leaves of Chukrasia tabularis. Helv Chim Acta 2008; 91: 2338-50.

71 Wang XN, Fan CQ, Yin S, Lin LP, Ding J, Yue JM. Cytotoxic terpenoids from Turraea pubescens. Helv Chim Acta 2008; 91: 510-9.

72 Liao SG, Zhan ZJ, Yang SP, Yue JM. Lathyranoic acid A: first secolathyrane diterpenoid in nature from Euphorbia lathyris. Org Lett 2005; 7: 1379-82.

73 Chen HD, He XF, Ai J, Geng MY, Yue JM. Trigochilides A and B, two highly modified daphnane-type diterpenoids from Trigonostemon chinensis. Org Lett 2009; 11: 4080-3.

74 Chen HD, Yang SP, He XF, Ai J, Liu Z, Liu HB, et al. Trigochinins A-C: three new daphnane-type diterpenes from Trigonostemon chinensis. Org Lett 2010; 12: 1168-71.

75 Chen HD, Yang SP, He XF, Liu HB, Ding J, Yue JM. Trigochinins D-I: six new daphnane-type diterpenoids from Trigonostemon chinensis. Tetrahedron 2010; 66: 5065-70.

76 Dong SH, Liu HB, Xu CH, Ding J, Yue JM. Constituents of Trigonostemon heterophyllus. J Nat Prod 2011; 74: 2576-81.

77 Dong SH, Zhang CR, Xu CH, Ding J, Yue JM. Daphnane-type triterpenoids from Trigonostemon howii. J Nat Prod 2011; 74: 1255-61.

78 Lin BD, Han ML, Ji YC, Chen HD, Yang SP, Zhang S, et al. Trigoxyphins A-G: diterpenes from Trigonostemon xyphophylloides. J Nat Prod 2010; 73: 1301-5.

79 Yin S, Su ZS, Zhou ZW, Dong L, Yue JM. Antimicrobial diterpenes from Trigonostemon chinensis. J Nat Prod 2008; 71: 1414-7.

80 Zhan ZJ, Fan CQ, Ding J, Yue JM. Novel diterpenoids with potent inhibitory activity against endothelium cell HMEC and cytotoxic activities from a well-known TCM plant Daphne genkwa. Bioorg Med Chem 2005; 13: 645-55.

81 Yang SP, Dong L, Wang Y, Wu Y, Yue JM. Antifungal diterpenoids of Pseudolarix kaempferi, and their structure-activity relationship study. Bioorg Med Chem 2003; 11: 4577-84.

82 Yang SP, Wu Y, Yue JM. Five new diterpenoids from Pseudolarix kaempferi. J Nat Prod 2002; 65: 1041-4.

83 Xiang Y, Zhang $\mathrm{H}$, Fan CQ, Yue JM. Novel diterpenoids and diterpenoid glycosides from Siegesbeckia orientalis. J Nat Prod 2004; 67: 1517-21.

84 Liu HB, Zhang H, Yu JH, Xu CH, Ding J, Yue JM. Cytotoxic diterpenoids from Sapium insigne. J Nat Prod 2012; 75: 722-7.

85 Xue JJ, Fan CQ, Dong L, Yang SP, Yue JM. Novel antibacterial diterpenoids from Larix chinensis Beissn. Chem Biodivers 2004; 1 : 1702-7.

86 Yuan T, Zhu RX, Yang SP, Zhang H, Zhang CR, Yue JM. Serratustones $A$ and $B$ representing a new dimerization pattern of two types of sesquiterpenoids from Chloranthus serratus. Org Lett 2012; 14: 
3198-201.

87 Yang SP, Gao ZB, Wang FD, Liao SG, Chen HD, Zhang CR, et al. Chlorahololides $\mathrm{A}$ and $\mathrm{B}$, two potent and selective blockers of the potassium channel isolated from Chloranthus holostegius. Org Lett 2007; 9: 903-6.

88 Yang SP, Gao ZB, Wu Y, Hu GY, Yue JM. Chlorahololides C-F: a new class of potent and selective potassium channel blockers from Chloranthus holostegius. Tetrahedron 2008; 64: 2027-34.

89 Yuan T, Zhang CR, Yang SP, Yin S, Wu WB, Dong L, et al. Sesquiterpenoids and phenylpropanoids from Chloranthus serratus. J Nat Prod 2008; 71: 2021-5.

90 Zhang S, Yang SP, Yuan T, Lin BD, Wu Y, Yue JM. Multistalides A and $\mathrm{B}$, two novel sesquiterpenoid dimers from Chloranthus multistachys. Tetrahedron Lett 2010; 51: 764-6.

91 Yang SP, Yue JM. Chloramultilide A, a highly complex sesquiterpenoid dimmer from Chloranthus multistachys. Tetrahedron Lett 2006; 47: 1129-32.

92 He XF, Zhang S, Zhu RX, Yang SP, Yuan T, Yue JM. Sarcanolides A and $B$ : two sesquiterpenoid dimers with a nonacyclic scaffold from Sarcandra hainanensis. Tetrahedron 2011; 67: 3170-4.

93 He XF, Yin S, Ji YC, Su ZS, Geng MY, Yue JM. Sesquiterpenes and dimeric sesquiterpenoids from Sarcandra glabra. J Nat Prod 2010; 73: 45-50.

94 Yin S, Xue JJ, Fan CQ, Miao ZH, Ding J, Yue JM. Eucalyptals A-C with a new skeleton isolated from Eucalyptus globules. Org Lett 2007; 9: 5549-52.

95 Su ZS, Yin S, Zhou ZW, Wu Y, Ding J, Yue JM. Sesquiterpenoids from Hedyosmum orientale. J Nat Prod 2008; 71: 1410-3.

96 Yang SP, Huo J, Wang Y, Lou LG, Yue JM. Cytotoxic sesquiterpenoids from Eupatorium chinense. J Nat Prod 2004; 67: 638-43.

97 Huo J, Yang SP, Ding J, Yue JM. Cytotoxic sesquiterpene lactones from Eupatorium lindleyanum. J Nat Prod 2004; 67: 1470-5.

98 Chen X, Zhan ZJ, Zhang XW, Ding J, Yue JM. Sesquiterpene lactones with potent cytotoxic activites from Vernonia chinensis. Planta Med 2005; 71: 949-54.

99 Xiang Y, Fan CQ, Yue JM. Novel sesquiterpenoids from Siegesbeckia orientalis. Helv Chim Acta 2005; 88: 160-70.

100 Fan CQ, Zhan ZJ, Li H, Yue JM. Eudesmane-type sesquiterpene derivatives from Saussurea conica. Helv Chim Acta 2004; 87: 1446-51.

101 Zhang H, Liao ZX, Yue JM. Five new sesquiterpenoids from Parasenecio petasitoides. Helv Chim Acta 2004; 87: 976-82.

102 Wang Y, Yang SP, Yue JM. Novel sesquiterpenes from the fungus Lactarius piperatus. Helv Chim Acta 2003; 86: 2424-33.

103 Liao SG, Yuan T, Zhang C, Yang SP, Wu Y, Yue JM. Cinnacassides A-E, five geranylphenylacetate glycosides from Cinnamomum cassia. Tetrahedron 2009; 65: 883-7.

104 Yin S, Chen X, Su ZS, Yang SP, Fan CQ, Ding J, et al. Harrisotones A-E, five novel prenylated polyketides with a rare spirocyclic skeleton from Harrisonia perforate. Tetrahedron 2009, 65: 1147-52.

105 Yin S, Fan CQ, Dong L, Yue JM. Psoracorylifols A-E, five novel compounds with activity against Helicobacter pylori from seeds of Psoralea corylifolia. Tetrahedron 2006; 62: 2569-75.

106 Fan CQ, Yue JM. Biologically active phenols from Saussurea medusa. Bioorg Med Chem 2003; 11: 703-8.

107 Yin S, Fan CQ, Wang Y, Dong L, Yue JM. Antibacterial prenylflavone derivatives from Psoralea corylifolia and their structure-activity relationship study. Bioorg Med Chem 2004; 12: 4387-92.

108 Gan LS, Yang SP, Fan CQ, Yue JM. Lignans and their degraded derivatives from Sarcostemma acidum. J Nat Prod 2005; 68: 221-5.

109 Fan CQ, Zhu XZ, Zhan ZJ, Ji XQ, Li H, Yue JM. Lignans from Saussurea conica and their NO production suppressing activity. Planta Med 2006; 72: 590-5.

110 Liao SG, Zhang BL, Wu Y, Yue JM. New phenolic components from Daphne giraldii. Helv Chim Acta 2005; 88: 2873-8.

111 Zhou ZW, Yin S, Wang XN, Fan CQ, Li H, Yue JM. Two new lignan glycosides from Saussurea laniceps. Helv Chim Acta 2007; 90: 951-6.

112 Zhang CR, Yang SP, Liao SG, Wu Y, Yue JM. Polyoxygenated cyclohexene derivatives from Uvaria rufa. Helv Chim Acta 2006; 89: 1408-16.

113 Liao SG, Wu Y, Yue JM. Lignans from Wikstroemia hainanensis. Helv Chim Acta 2006; 89: 73-80.

114 Yang SP, Yue JM. Five new quassinoids from the bark of Picrasma quassioides. Helv Chim Acta 2004; 87: 1591-600.

115 Yang SP, Yue JM. Two novel cytotoxic and antimicrobial triterpenoids from Pseudolarix kaempferi. Bioorg Med Chem Lett 2001; 11 : 3119-22.

116 Cai JH, Han C, Hu TC, Zhang J, Wang FD, Liu YQ, et al. Peptide deformylase is a potential target for anti-Helicobacter pylori drugs: reverse docking, enzymatic assay and X-ray crystallography validation. Protein Sci 2006; 15: 2071-81.

117 Liu H, Li Y, Song MK, Tan XJ, Cheng F, Zheng SX, et al. Structurebased discovery of potassium channel blockers from natural products-virtual screening and electro-physiological assay testing. Chem Biol 2003; 10: 1103-13.

118 Tong YG, Zhang XW, Geng MY, Yue JM, Xin XL, Tian F, et al. Pseudolarix acid $B$, a new tubulin-binding agent, inhibits angiogenesis by interacting with a novel binding site on tubulin. Mol Pharmacol 2006; 69: 1226-33.

119 Li MH, Miao ZH, Tan WF, Yue JM, Zhang C, Lin LP, et al. Pseudolaric acid $B$ inhibits angiogenesis and reduces hypoxia-inducible factor $1 \alpha$ by promoting proteasome-mediated degradation. Clin Cancer Res 2004; 10: 8266-74.

120 Tan WF, Zhang XW, Li MH, Yue JM, Chen Y, Lin LP, et al. Pseudolarix acid $B$ inhibits angiogenesis by antagonizing the VEGF-mediated antiapoptotic effect. Eur J Pharmacol 2004, 499: 219-28.

121 Yang SP, Cai YJ, Zhang BL, Tong LJ, Xie H, Wu Y, et al. Structural modification of an angiogenesis inhibitor discovered from traditional Chinese medicine and a structure-activity relationship study. J Med Chem 2008; 51: 77-85.

122 Zhang BL, Fan CQ, Dong L, Wang FD, Yue JM. Structural modification of a specific antimicrobial lead against Helicobacter pylori discovered from traditional Chinese medicine and a structure-activity relationship study. Eur J Med Chem 2010; 45: 5258-64.

123 Wang FD, Yue JM. Novel and highly efficient syntheses of (+)-and (-)-dihydrokawain using sonochemical Blaise reaction as the key step. Eur J Org Chem 2005; 2005: 2575-9.

124 Zhang BL, Wang FD, Yue JM. A new efficient method for the total synthesis of linear furocoumarins. ChemInform 2006; 37: 567-70.

125 Wang FD, Yue JM. Total synthesis of $R-(+)$-kavain via $(\mathrm{MeCN})_{2} \mathrm{PdCl}_{2}-$ catalyzed isomerization of cis-double bond and sonochemical Blaise reaction. SynLett 2005; 13: 2077-9. 